\title{
ENTRE LA INTEGRIDAD Y LA SEGREGACIÓN. LA VIOLENCIA Y LA CONFLICTIVIDAD SOCIO-ECONÓMICA EN LA JUDERÍA DE INCA (MALLORCA, SIGLO XIV)
}

\author{
Jorge Maíz Chacón ${ }^{1}$ \\ (UNED Illes Balears)
}

\section{RESUMEN}

En el texto se analiza la presencia de judíos en el Reino de Mallorca, especialmente en la población de Inca. A lo largo de la Edad Media, la minoría hebrea se instalará con diferente suerte en el interior de Mallorca, conociendo una etapa de gran crecimiento económico y demográfico. En el tránsito del siglo XIII al XIV, la minoría judía poco a poco pasará de una etapa de convivencia y tolerancia a otra de gran conflictividad entre cristianos y judíos. Los problemas se irán generalizando hasta la ruptura final de esa 'convivencia' con el asalto y el saqueo del barrio judío de Inca en el año 1391.

Palabras clave: Judíos, Reino de Mallorca, Inca, Siglo XIV, Economía, Sociedad, Violencia y Convivencia.

\section{ABSTRACT}

The text discusses the presence of Jews in the Kindom of Mallorca, especially in the town of Inca. Throughout the Middle Ages, the jewish minority will be installed with different fate inside Majorca, knowing a period of great economy and population growth. In the transition from the thirteenth to fourteenth century, the jewish minority gradually passs from one stage

1 Doctor en Historia. Profesor tutor. UNED Illes Balears. Edifici Guillem Mesquida. Camí Roig, s/n. 07009. Palma de Mallorca.C.e: jmaiz@palma.uned.es 
of coexistence and tolerance to another major conflict between christians and jews. The problems will be widespread until the final rupture of the 'coexistence' with the assault and looting the jewish quarter of Inca in 1391.

Keywords: Jews, Kingdom of Mallorca, Inca, XIV century, Economy, Society, Violence and Coexistence.

\section{PRESENCIA Y ESTABLECIMIENTO DE LOS PRIMEROS NÚCLEOS JUDÍOS EN LA VILLA DE INCA}

La presencia de los judío en la villa de Inca se remonta documentalmente a la llegada en 1229 de las tropas de Jaime I el Conquistador a la isla de Mallorca. Sin referencias históricas o arqueológicas de etapas anteriores que puedan justificar históricamente una presencia anterior, nos remitimos a los documentos del reparto de Mallorca, en los que se otorgan una cantidad de tierras considerables a los judíos en los términos de la antigua área administrativa musulmana denominada Inkan. Así, en el Capbreu del Repartiment se otorgan las siguientes alquería y rahales: Abenbasso (3 Jovades), Vualà (4 Jovades), Naya (4 Jovades), Docax (5 Jovades), Raalatim (4 Jovades) y Abinxuaip (Jovades), todas ellas sin asignación nominal concreta, pasarán a manos de los judíos ${ }^{2}$. Del mismo modo, la primera referencia documental sobre los judíos de Inca, al margen de dicho reparto de tierras que ya hemos comentado, y que podría atestiguar la existencia de comunidades anteriores a la ocupación cristiana, data del año 1240, cuando volvemos a tener referencias de dicha presencia en la villa. En la misma, tenemos la referencia indirecta de la presencia del judíos realizando algunas operaciones económicas no muy significativas, al menos por el momento. De la misma manera, los pocos datos demográficos que disponemos del siglo XIV, éstos son anteriores a la peste negra de 1348. En ambos casos, tanto el Morabatí de 1329 como el de 1336 reducen la presencia de ciudadanos judíos a cifras que rondan el 2 y el $3 \%$ del total de habitantes de la villa. Por tanto, las conclusiones que podemos extraer serían un tanto especulativas, ya que no hay otros datos que puedan corroborar las hipótesis planteadas. En este sentido, bien podríamos

2 PÉREZ MARTÍNEZ, Lorenzo: "Corpus documental balear: reinado de Jaime I", Fontes Rerum Balearium [Palma], I (1977), p. 83-86, doc. 74.

Según el estudio de Guillem Rosselló Bordoy (Mallorca musulmana, Edicions UIB, Palma, 2007) del Códice 18 del Arxiu del Regne de Mallorca, los judíos recibieron en el mismo reparto las alquería de Adducutz (6 jovades) y Abinxuaip (con 5 jovades). Aproximadamente, según los dos estudios recibirían en el término de Inca entre 20 y 23 jovades. 
indicar que muchos judíos establecidos en Inca no pagaban el Morabatî3; también podría darse el caso de otros que residían en zonas rurales, en otros núcleos; o bien que la comunidad judía de Inca era escasa y pequeña. En todos los casos, se nos ocurren y se nos plantean problemas por lo cual trataremos de analizar los datos que tenemos en años posteriores. Estos datos nos ofrecen una realidad demográfica que superaría por poco el centenar de individuos y que representa también un porcentaje de familias judías que no podrían pagar los morabatines y el patrimonio sería inferior a 10 libras. Las pequeñas diferencias numéricas establecidas entre los dos datos, entre 1329 y 1336, podrían explicarse desde una óptica religiosa y económica ${ }^{4}$. Para estos las presiones que están estableciendo algunas familias cristianas serían cada vez más grandes y tratarían de evitar la importante tarea comercial y económica que realizan los judíos en Inca. Del mismo modo, también sería lógico entender que las presiones vendrían desde las instancias religiosas que nunca acabaría de entender la alianza en la cual se establecía normalmente la relación entre monarquía y comunidad judía.

Las consecuencias de la peste negra en Mallorca ya han sido analizadas de forma detallada ${ }^{5}$, pese a ello, muy poco conocemos sobre las consecuencias de la misma en la villa de Inca, y menos aún sobre su incidencia directa sobre la minoría judía en esta zona. Si bien es cierto, documentalmente tenemos algunas referencias que nos pueden ayudar a trazar unas primeras líneas interpretativas que nos llevarían a pensar en la muerte de un considerable número de judíos que poseían prestamos con otros habitantes de Mallorca. Así por ejemplo, Jucef Rapapa, judío de la zona de Inca que recibía en estos momento la cantidad de 20 libras de su mujer Dolça que había muerto en los tiempos de la mortalidad, entendiéndose en la época de la peste negra ${ }^{6}$. La difícil situación que se derivaría de la etapa inmediatamente posterior a la mortandad catastrófica de 1348, tensó las relaciones entre los colectivos judíos internamente también. En esta misma línea, hay constancia de las disputas entre los judíos de Palma y los establecidos en Inca por el pago

3 FERRETJANS LLOMPART, Antelm: Demografia d'Inca en el primer terç del segle XIV, Ajuntament d'Inca, Inca, 1990.

El autor reduce los judíos pagadores al $77 \%$ en el año 1329 y al $61 \%$ en el morabatín de 1336.

4 LLABRÉS I MARTORELL, Pere-Joan; ROSSELLÓ I VAQUER, Ramon: Inca en la història (1229-1349), Ajuntament d'Inca, Inca, 1998, p. 236.

5 SANTAMARÍA ARÁNDEZ, Álvaro: "La peste negra en Mallorca", VIII Congreso de Historia de la Corona de Aragón, 2, Zaragoza, 1969, pp. 103-132; LÓPEZ DE MENESES, A.: "Documentos acerca de la peste negra en los dominios de la Corona de Aragón", Estudios de Edad Media de la Corona de Aragón, 6, 1956, pp. 291-448.

6 Arxiu del Regne de Mallorca, Arxiu Històric, 23, f. 18, 25v. 
de unas cantidades económicas por parte de estos últimos, encontrándonos con algunos habrían muerto como consecuencia de la citada epidemia ${ }^{7}$. Otra de las consecuencias de la peste negra en Mallorca y concretamente para la minoría judía sería el retraso en la implantación de la nueva aljama de Inca, interrumpiéndose de este modo las órdenes del año 1346 en las que el propio monarca sugería dicha creación mediante un estudio inicial ${ }^{8}$. También podemos pensar que algunos de los judíos que no pagan los morabatines y que no poseían cantidades económicas que reclamar pudieron morir durante esa misma epidemia, pero sobre los mismos las fuentes no nos han dejado testimonios.

A pesar de los pequeños cambios, entendemos que no habría una huída de la villa motivada por dichas presiones, además, en épocas posteriores tenemos referencias documentales que nos hablan de la masiva presencia de comunidades judías en dicho lugar, viviendo diseminados -hacia 1346- entre cristianos, provocando así problemas por dicha situación9. Igualmente, si atenemos a los datos numéricos del Llistat d'Homes d'Armes de la Part Forana de 1359, la que se refiere a Inca, contabiliza un total de 30 judíos, una cifra importante ya que representa en este momento un porcentaje de población superior al $4 \%$, aunque no deja de ser un dato minoritario ${ }^{10}$. Transcurridos diez años de la peste negra, la población de hombres judíos en Inca, no sólo habría decaído sino que crecía en número. Por tanto, los datos nos ofrecen un crecimiento demográfico de los judíos del término, un ascenso que se estaría consolidando durante la segunda mitad del siglo XIV, creciendo en momento de dificultad económica, religiosa y de cohabitación, hasta tal punto que se erigen en barrio separado y en aljama jurídicamente independiente de la palmesana.

\section{LA LUCHA POR EL CONTROL ECONÓMICO}

Durante los siglos XIII y especialmente durante el XIV, las autoridades locales de diversas villas rurales irán ampliando sus necesidades económicas y también tratarán a toda costa de optimizar sus mecanismo tributarios. De este modo, en Inca al igual que en otros lugares se procederá a la fiscali-

7 Arxiu del Regne de Mallorca, Arxiu Històric, , 9, 18v

8 LLABRÉS I MARTORELL, Pere-Joan; ROSSELLÓ I VAQUER, Ramon: Inca en la història,... p. 198.

9 Arxiu del Regne de Mallorca, Lletres Reials, 11, f. 211.

10 Arxiu Diocesà de Mallorca, MSL/307.

Ver: MIRALLES I MONTSERRAT, Joan: Corpus d'antropònims mallorquins del segle XIV, Institut d'Estudis Catalana, Barcelona, 1997. 
zación de todos los sujetos y actividades económicas que en sus dominios se realizan. Al igual que en Palma, en Inca el baile obligará a los judíos al pago por determinados conceptos. Por ejemplo, se obligará a Vidal Sagrasa a pagar por lo negocios que realiza en dicha villa ya que hasta el momento pese a no residir en Inca realizaba actividades en ella y pagaba tributos en Ciutat $^{11}$. La situación parece ser algo habitual ya que en las tallas y questias muchos judíos decían habitar en Palma, evitando de este modo también la fiscalidad establecida en Inca ${ }^{12}$. Para finales de año, el baile habría acordado con los secretarios de la aljama de Ciutat que aquellos judíos que habitasen, residieran o negociaran en Inca debían contribuir a las tallas de dicha ciudad y contribuir de esta manera a las arcas locales ${ }^{13}$.

En estos momentos, la situación que está atravesando el sistema fiscal del reino de Mallorca no es del todo solvente. Desde 1349, los ingresos no son suficientes para hacer frente a las cargas y a los gastos comunes de los que la administración se debe hacer cargo. La situación no es novedosa, ya en años anteriores, por ejemplo en 1321 y 1330, habían ocurrido situaciones similares, por ello, las administraciones acudirán con cierta asiduidad al crédito. En este sentido, los préstamos que realizan los judíos no serán exclusivos con los administradores del reino ${ }^{14}$. En las zonas rurales de Mallorca, la situación económica y financiera tampoco es muy buena, buena muestra de ello lo encontramos en la villa de Inca, en la misma en el año 1362 encontraremos un número de créditos muy elevado y unos intereses que para ese año superan las 169 libras $^{15}$. Es evidente que entre el campesinado de Mallorca se genera una gran dependencia económica con ciertos mercaderes y prestamistas judíos. Los primeros compraban en ocasiones las cosechas a unos precios bajos antes de la siembra y los segundos ayudaban económicamente a los campesinos en sus momentos más difíciles, en época

11 Arxiu del Regne de Mallorca, Lletres Comuns, 16, 1356, f. 65v.

A instancia del mismo judío, el rey mediante Guillem de Llagostera escribirá al baile de Inca para dictaminar sobre esta situación y sobre las tasaciones relaciadas entre judíos.

Ver: PONS PASTOR, A.: Los judíos del reino de Mallorca durante los siglo XIII y XIV, Miquel Font Editor, Palma, 1984, I, doc. 24.

12 Idem., f. 33v.

13 Arxiu del Regne de Mallorca, Lletres Comuns, 17, f. 17.

14 CATEURA BENNÀSSER, Pau: "El crèdit municipal en el regne de Mallorca (13551374)", El crèdit i el sistema financer del Regne de Mallorca (segles XIV-XV), Universitat de les Illes Balears, Palma, 2009, pp. 11-40.

15 Arxiu Diocesà de Mallorca, MSL/281, f 42-43v .

Documento citado en: CATEURA BENNÀSSER, Pau: "El crèdit municipal en el regne de Mallorca (1355-1374)", El crèdit i el sistema financer del Regne de Mallorca (segles XIV-XV), Universitat de les Illes Balears, Palma, 2009, pp. 11-40. 
de necesidad de liquidez económica o en momentos de malas cosechas ${ }^{16}$. Los judíos son bien conocedores de la situación del campo mallorquín, de hecho, las comunidades establecidas en Muro, Manacor, Felanitx o la propia Inca realizarán actividades relacionadas con los ciclos agrarios y relacionados también con los mercados y con la compra-venta de productos agrarios ${ }^{17}$. En Mallorca, existe un reducido número de judíos que realizan numerosas actividades en estas redes rurales de venta y producción de productos. En esta relación que podríamos denominar de amor y odio, se genera el desarrollo de una gran enemistad hacia las familias pudientes del colectivo judío, un odio y una envidia en ocasiones que serán la perfecta base para la creación de esa mentalidad poco favorecedora hacia la minoría judía en el área de Inca.

La coexistencia en la zona de Inca de diversos grupos religiosos, uno mayoritario -el cristiano- y otro minoritario -el judío- se tensaría a mediados del siglo XIV. Pocos años después del desastre demográfico y económico causado por la epidemia de 1348, localizamos algunos significativos enfrentamientos entre ambas comunidades. Así en octubre de 1353, el gobernador Gilabert de Centelles habría recibido quejar por parte de los Jurats de Inca, en las mismas se señalaba la situación de peligrosidad ante la presencia de judíos en la villa dispersos por la población y que daban continuos motivos de escándalo ${ }^{18}$. Aunque desconocemos la verdadera naturaleza de estos escándalos, es evidente que los problemas irían in crescendo de forma continua. Parece que la situación y la conflictividad ya estaría originada durante la celebración de la pascua cristiana en el mismo año. De este modo, desde las instituciones judías se enviaría una súplica al gobernador de Mallorca reclamando protección con la finalidad de evitar estos insultos y situaciones de peligro, que seguramente eran bastante habituales ${ }^{19}$. Los secretarios de la aljama, en representación de los judíos de Inca, reclamaban un aumento del número de protectores del barrio, ya que el saig de la villa sería del todo insuficiente para contener los problemas existentes entre ambas comunidades. Esta reclamación y la explícita demanda de insuficiencia en la protección sobre la minoría judía, nos hace pensar que seguramente existieron antecedentes en años anteriores de los que por el momento no tenemos constancia documental y que evidenciarían la escasa eficiencia del dispositivo de

16 MAIZ CHACON, J.: Los judíos de Baleares en la baja edad media. Economia y politica, Netbiblo - UNED, A Coruña, 2010.

17 MAIZ CHACON, J.: "Els mètodes crediticis jueus a la Mallorca medieval", CATEURA BENNÀSSER, P. (ed.): El crèdit i el sistema financer del Regne de Mallorca (segles XIVXV), Edicions UIB - Consell de Mallorca, Palma, 2009, pp. 147-163.

18 Arxiu del Regne de Mallorca, Lletres Comuns, Extraordinaris, 1353, sf.

19 Arxiu del Regne de Mallorca, Arxiu Històric, Lletres Comuns, 13, f. 55. 
seguridad en el barrio judío tanto de Inca como de Palma, aunque para ello tendríamos que generar una visión mucho más amplia de la década de los sesenta y setenta del siglo XIV.

\section{LA CORTA AUTONOMÍA DE LA ALJAMA DE INCA}

Sin ninguna duda, la separación y la creación de un nuevo barrio judío en Inca y la delegación de los secretarios de la aljama de Palma en los judíos de Inca como representantes autónomos supuso grandes cambios en la villa. Estos cambios, suponían un reconocimiento del crecimiento de dicha comunidad durante el siglo XIV, un aumento que no estaría únicamente relacionado con las familias judías que se establecían, sino también relacionado con las actividades económicas que desarrollaban, haciendo de Inca un paso obligado para las zonas rurales del entorno y creando a su alrededor un mercado considerable muy dinámico comercial y económicamente.

Igualmente, la tensa circunstancia que acompañará al asalto y fin de la aljama balear de 1391 acabará de forma brusca con el crecimiento y con la autonomía de la aljama de Inca. A pesar de que autonomía asumida por la aljama de Inca apenas durará diez años, este tiempos sería suficiente para generar una estructura política y administrativa suficientemente compleja como para albergar en su seno órganos de representación y articulación de los judíos de la zona. De hecho, en el verano de 1328, el turo del monarca Jaime III escribía una carta al lugarteniente real, Arnau de Cardellac, al que le pedía que se hiciera justicia sobre una reclamación que habría realizado la Universitat de los judíos de Inca ${ }^{20}$. En el mencionado texto se daría a entender que los judíos de Inca, además de recibir el título de Universitat, realizaban tallas y questias propias y que como pasaba en otros lugares y años, había judíos que no podían pagarlas. Unos alegaban que ya realizaban el citado pago en Palma, mientras que otros consideraban estar exentos del citado pago. Dentro de los que recibirían el visto bueno por parte de la administración estaría Vidal Sagrasa, que en 1356 recibía una carta del baile de Inca para no contribuir a la questias pagadoras en la citada villa ${ }^{21}$.

En enero de 1383, Omer Leví y Mose Leví recogían el testigo y se convertían legalmente en los secretarios de la aljama de Inca, completando así un complejo proceso hacia la autonomía de la misma ${ }^{22}$. El evidente desarrollo de la comunidad judía de Inca conllevaría también para finales de siglo la apari-

20 Arxiu del Regne de Mallorca, Lletres Reials, 7, f. 219v-220.

Documento citado en: ROSSELLÓ VAQUER, Ramon: Història d'Inca..., p. 236-237.

21 Arxiu del Regne de Mallorca, Lletres Comuns, 16, f. 65v.

22 Arxiu del Regne de Mallorca, Arxiu Històric, 49, f. 2v i 43. 
ción de una escuela rabínica, que debía estar situada en la sinagoga local en la que localizamos a Jucef Ben Barahon ${ }^{23}$. De la misma manera, las evidencias del crecimiento y de la importancia que asume la citada aljama está también relacionada con la existencia de un cementerio judío, el cual bajo el nombre de 'fossar dels jueus' aparecería aún en el año 1393, utilizándose para enterrar los restos de huesos y cuerpos (si especificar el número) del albergue que tenía en Inca Bofill de la Argentería ${ }^{24}$.

\section{DE LAS PREDICACIONES A LA RUPTURA DE LA CONVIVENCIA}

Si analizamos detenidamente el proceso que nos llevaría a la ruptura de la convivencia entre las minorías judía y cristiana en la villa de Inca evidenciamos que no se trata de un proceso exclusivo de dicho territorio, de hecho, la gran mayoría de especialistas sobre el judaísmo medieval coinciden en señalar que durante el siglo XIV se rompe la teoría de la "convivencia armónica" entre ambas religiones ${ }^{25}$. Las evidencias inmediatamente posteriores al año 1348 ya nos advierten de la existencia de una situación poco pacifica. Parece que desde principios de 1349 el gobernador debía reclamar que los judíos de Inca no fueran molestados durante las festividades, de hecho, parece que muchos judíos moradores de la zona iban a Palma para celebrar las festividades entre sus parientes y amigos y que estos movimientos no eran muy bien recibidos por parte de algunos cristianos. ${ }^{26} \mathrm{Tal}$ y como hemos señalado, parece ser que la peste negra de 1348, además de otras consideraciones, servirían para aumentar la hostilidad hacia dicha minoría. Aunque por el momento no hemos localizado referencias sobre la llegada del mensaje del cronista Jean de Venetto a Mallorca, es lógico entender e incluso pensar que si en las zonas continentales se están produciendo acusaciones contra los judíos con motivo de la fatal epidemia, esta nuevas noticias podrían llegar a Mallorca por los múltiples canales que las comunican comercialmente y también mentalmente con otras localidades ${ }^{27}$.

23 FAJARNÉS, Enrique: "Jucef-Ben-Barahon. Rabí de la Escuela de los judíos de Mallorca: su familia y sus bienes (1392)", Boletín de la Sociedad Arqueológica Luliana [Palma], VII (1898), pp. 376-377.

24 Arxiu del Regne de Mallorca, Arxiu Històric, 66, f. 62v.

25 NIRENBERG, D.: "Violencia, memoria y convivencia: los judíos en el medioevo ibérico", Memoria y Civilización: Anuario de historia de la Universidad de Navarra, Pamplona, 2, 1999, pp. 31-53; BEINART, Haim: Los judíos de España, MAPFRE, Madrid, 1993.

26 Arxiu del Regne de Mallorca, Arxiu Històric, 11, f. 12.

Documento citado en: ROSSELLÓ VAQUER, Ramon: Història d'Inca..., p. 241.

27 El cronista Jean Venette, señalaba en sus crónicas del siglo XIV que los judíos eran acusados de propagar esta epidemia. Ver: The chronicle of Jean de Venette, Columbia University Press, Nova York, 1953. 
La situación es realmente compleja, ya que si analizamos el universo local encontraremos a una gran cantidad de individuos cristianos que tienen prestado o que están endeudados de formas diferentes con los judíos. Sirva como ejemplo algunos de los identificados en el año 1347, en el que Arnau Riera, Guillem Croquell y Bernart Subirats tendrán deudas con los Mosse, una importante familia judía de Inca que posteriormente tendrá importantes cargos en la aljama local ${ }^{28}$. La década de los años cincuenta es especialmente tensa, debemos entender que la situación entre ambas comunidades se agudiza por la fatal peste negra y también por la difícil situación económica de muchas familias del campo mallorquín, las cuales han perdido parte de sus miembros o bien están endeudadas con algunos judíos y ven como ahora sus herederos siguen reclamando las deudas años tras años a las autoridades. Las peticiones de ayuda o de vigilancia durante las festividades cristianas de Semana Santa serían tan habituales en Inca como en otros lugares del interior insular. De hecho, de casi todos los años aparecen constataciones documentales sobre las peticiones de ayuda y de súplica por parte de los secretarios de la aljama para que se eviten las injurias y los alborotos en torno a dicha minoría, tal y como ocurre en $1353^{29}$ i $1354^{30}$. Antes de la Semana Santa de 1357, el gobernador ante la instancia de las autoridades judías, reclamará y pedirá al baile de Inca que guarde a los judíos de dicha villa durante la festividad del Viernes Santo ${ }^{31}$. La tensión entre ambas comunidades era habitual y se concentraba no de manera exclusiva en la festividad de Pascua, también encontramos reclamaciones al baile de Inca para que los judíos pudieran trabajar durante la festividad de San Nicolás y que no tuvieran un trato vejatorio durante la misma ${ }^{32}$. En la Semana Santa de 1359, el gobernados también enviará al baile de Inca una misiva para que trate de evitar las continuas disputas que se producen en dichas fechas entre cristianos y judíos en su jurisdicción ${ }^{33}$.

A finales de 1360, Pedro el Ceremonioso otorgará una licencia para predicar la palabra al converso Nicolau de Gracia ${ }^{34}$. No sabemos con exactitud si se trata de la primera ocasión en la que se realizan este tipo de predicaciones en Mallorca, ya que con anterioridad también existieron licencias para predicar contra sarracenos y judíos durante el reinado de Jaime I el Conquistador

28 Arxiu del Regne de Mallorca, Notari Guillem Mulner, M-78, f. 1v, 11v i 46v.

29 Arxiu del Regne de Mallorca, Arxiu Històric, Lletres Comuns, 13, f. 55.

30 Arxiu del Regne de Mallorca, Arxiu Històric, Lletres Comuns, 14, f. 67v.

31 Arxiu del Regne de Mallorca, Arxiu Històric, Lletres Comuns, 17, f. 154v.

32 Arxiu del Regne de Mallorca, Arxiu Històric, Lletres Comuns , 21, f. 4.

33 Arxiu del Regne de Mallorca, Arxiu Històric, Governació, 21, f. 45

34 Arxiu del Regne de Mallorca, Lletres Reials, 1362, f. 245. 
en sus territorios. Las predicaciones contra la minoría judía solían realizarse los domingos o los sábados y tenían por objetivo la propagación de la fe cristiana. Con estas disposiciones, entendemos que las autoridades se veían obligadas a legislar para evitar enfrentamiento y alborotos que en ocasiones se organizaban y que no favorecían para nada la coexistencia entre dichos grupos religioso ${ }^{35}$. Para evitar la salida de los judíos de la judería, los reyes de la Corona de Aragón durante el siglo XIV disponían predicaciones que se hacían en el mismo barrio e incluso en el interior de las sinagogas ${ }^{36}$.

Transcurridos unos meses, este mismo converso se dirigiría a las comunidades judías dispersas a los largo de la geografía mallorquina, esta nueva petición incluirá evidentemente una nueva visita a Inca. Nicolau de Gracia, tenía entre sus objetivos tratar de convencer y convertir también a aquellas comunidades judaicas alejadas de la gran aljama de Palma. De este modo, en julio de 1361 hay una carta del gobernador a los bailes de Mallorca con la finalidad de evitar situaciones tensas y que estos judíos -con motivo de dichas predicaciones- fueran maltratados ${ }^{37}$ o injuriados ${ }^{38}$.

Las nuevas peticiones y las problemáticas que se van produciendo en la década de los setenta coinciden cronológicamente con la grave crisis del campo mallorquín en estas mismas fechas. Durante los años 1373 y 1375 se encadenan años de malas cosechas y un aumento del endeudamiento entre el campesinado, un grupo que cada vez se encontrará más ahogado por los créditos que en parte tiene establecidos con algunas familias judías dedicadas a tales efectos. En 1373, nuevamente durante las vigilias de Semana Santa se producirán incidentes en el barrio judío de Inca, en este caso se denuncia por parte de judíos haber padecido apedreamientos y otros maltratos ${ }^{39}$. A nuestro entender, la crisis agrícola iría ampliando esta tensa situación, de hecho en 1370, antes de la citada crisis agrícola, el monarca habría pedido ayuda a las autoridades de Ciutat de Mallorques para sofocar las calumnias que se están produciendo contra los judíos, especialmente motivadas por personas endeudadas con los mismos ${ }^{40}$. La tensión señalada, junto con la crisis agrícola, se unirá en esta localidad al malestar entre los ciudadanos cristianos por la

35 RIERA I SANS, J.: "Les Ilicéncies reials per predicar ais jueus i ais sarraïns (segles XIII-XIV)", Calls, 2, 1987, págs. 113-143.

36 Bulletí de la Societat Arqueologica Lul-liana, 1895-1896.

En Valencia, en el año 1333 se cita por ejemplo a Jimeno Pérez, quién realizara predicaciones en el Palacio Episcopal y también en la Sinagoga de Mallorca.

37 Arxiu del Regne de Mallorca, Lletres Comuns, 23, 1361-1362, f. 50.

38 Idem., f. $62 \mathrm{v}$.

39 Arxiu del Regne de Mallorca, Arxiu Històric, 39, f. 99v.

40 FITA, Fidel; LLABRÉS, Gabriel: "Privilegios de los hebreos mallorquines en el Códice Pueyo", Boletín de la Real Academia de la Historia [Madrid], XXXVI (1900), doc. 86. 
construcción de un nuevo barrio judío. En estos años, el monarca también recibiría quejar por parte de los ciudadanos de la villa, ya que la ventas que se están produciendo para la instauración del nuevo barrio se están produciendo bajo coacciones y engaños ${ }^{41}$.

La relación con la situación económica y con la crisis agrícola existente también está recogida en los testimonios documentales conservados. Parece ser que en el 1374, el infante Juan exigiría a la Universitat de Mallorca que protegiera a la población judía de los posibles alborotos y conflictos que se estaban produciendo con motivo de la situación y de la carestía de pan que recaía sobre Mallorca ${ }^{42}$. Era bastante lógico señalar que los judíos, quienes ya habían sido señalado como causantes de la fatalidad de la peste, eran los causantes de dicha hambre entre sus conciudadanos, convirtiéndose así en el perfecto chivo expiatorio del momento. De hecho, en el interior de Mallorca, hay muchos de los productores de cereales tenían deudas contraída con los judíos o bien tenían las cosechas compradas antes de la recogida. Además, hay grandes mercaderes judíos que importan cereales y con ello de forma indirecta controlan su venta y el precio de los mismo ${ }^{43}$. Parece ser que la situación habría llegado a tal extremo que el propio monarca, Pedro IV, durante este mismo año pediría a dicha institución que los judíos fueran protegidos ya que en ellos estaba la solución a la crisis, alegando que eran los que compraban galeras llenas de cereal que procedían de Barcelona o de otros de los múltiples lugares entre los que tenían contactos ${ }^{44}$.

Durante la década siguiente asistiremos a enfrentamientos entre diversas familias por el control de la aljama balear. Las luchas entre los clanes Faquim y Natjar generarán incluso el intervencionismo real, el cual no se mostraría dispuesto a perder el control indirecto que ejerce ocasionalmente sobre las instituciones judías ${ }^{45}$. La familia Faquim, participa activamente en el conflicto de la ubicación del barrio judío de Inca y también en la estimación que en dicha villa se realizaría allá por $1363^{46}$. Diversos miembros de este bando

41 PONS, Antoni: "Erección del Call en Inca de Mallorca: su lenta y fatigosa gestación (siglo XIV)", Sefarad [Madrid], 1955, pp. 69-87.

42 FITA, Fidel; LLABRÉS, Gabriel: "Privilegios de los hebreos mallorquines..., doc. 92.

43 Arxiu del Regne de Mallorca, Governació, 44, f. 306v.

En el año 1379, el judío Omar Bennono pedía a los bailes de las localidades de Felanitx y de Alarón que le pagaran las deudas que tenían contraídas con él, algunos ciudadanos o bien que les remitieran dichas cantidades en cereales.

44 FITA, Fidel; LLABRÉS, Gabriel: "Privilegios de los hebreos mallorquines..., doc. 93.

45 Arxiu de la Corona d'Aragó, Cancelleria Regia, 1.438, f. 94-94v.

46 Arxiu del Regne de Mallorca, Governació, 446, f. 126-129v i Arxiu Històric, 27, f. 112. 
son denominados "familiares reales" en $1377^{47}$ y en $1390^{48}$, con lo que ello comportaba. Los Faquim, serían una importante familia de mercaderes con intereses políticos en los órganos de representación y de decisión judaicos, con buenas relaciones con la monarquía y que no desearían quedar al margen de la creación de la nueva aljama inquera. Igualmente estaban muy relacionados con el mercadeo de cereales, algo fundamental en las zonas rurales del interior de Mallorca. En el año 1370 reciben 400 libras por parte de la tesorería del reino para una embarcación de grano que habrían perdido en tierras de Cerdeña al ser capturada por sus autoridades ${ }^{49}$. Frente a los mismos la familia Natjar, también con intereses comerciales y con créditos repartidos en gran parte de Mallorca. De hecho las actividades de este otro clan incluye incluso préstamos a la Universitat en diversas época ${ }^{50}$, así como otros repartidos en Felanitx, Campanet, Muro o en la propia villa de Inca, localidad en la que tendrán muchas reclamaciones de impagos después del asalto a la judería en el año 1391. No debemos olvidar que este es el contexto en el que se produce la segregación de la aljama de Inca, pudiendo ampliar a dicho contexto este complejo momento de luchas y disputas internas. En 1382, 1385, 1386, 1388 y 1389 se producirán nuevas y continuas peticiones de protección por parte de los judíos al gobernador, señalando asimismo la problemática del Viernes Santo ${ }^{51}$. Dicha celebración es una de las principales conmemoraciones del cristianismo, en este día se recordaba la muerte de Jesús de Nazaret ${ }^{52}$, momento que sería aprovechado para recordar a los judíos las malas artes de algunos, haciendo así extensible al conjunto de la comunidad la condición de prestamistas o incluso de usureros. Además, son muchos los historiadores los que inciden en la idea y en la condición que se atribuye a los judíos como "deicidas", por tanto, no sería mejor día para recordarles tal hazaña que hacerlo de forma violenta en diversos lugares tal evento entre los que Inca también se encontraría.

47 Arxiu de la Corona d'Aragó, Cancelleria Regia, 1.437, f. 183v-184.

48 RIERA I SANS, Jaume: "Cresques Abraham, jueu de Mallorca, mestre de mapamundis i de brúixoles", L'Atlas Català de Cresques Abraham, Diàfora, Barcelona, 1975, pp. 1422.

49 Arxiu de la Corona d'Aragó, Cancelleria Regia, 1.678, f. 95.

50 Arxiu Diocesà de Mallorca, MSL, 281, f. 32vv.

51 MAIZ CHACON, J.: Los judíos de Baleares...

52 VALDEÓN BARUQUE, Julio: "El siglo XIV: la quiebra de la convivencia entre las tres religiones", Cristianos, musulmanes y judíos en la España medieval. De la aceptación al rechazo, Ámbito - Fundación Duques de Soria, Valladolid, 2004, pp. 125-148; FAÜ, Jean-François: L’image des juifs dans l'art chrétien médiéval, Maisonneuve \& Larouse, Paris, 2005; COHEN, J.: "The jews as the killers of Christ in the latin tradition, from Augustine to the Fiars", Traditio, 30, 1983, pp. 1-27. 
En 1387 se debieron producir algunas reuniones de carácter clandestino en localidades del interior de Mallorca, en la mismas -en las que se documenta la presencia de armas- el gobernador real ante el aumento de la tensión entre ambas comunidades tuvo que tomar medidas. Envió cartas a los bailes de Felanitx, Manacor, Porreras y Sant Joan, además de Inca para que se trataran de impedir este tipo de reuniones ${ }^{53}$. La tensa situación de la aljama y de la judería de Inca, serían tan alarmantes que algunos, incluso algunos conversos, se dedicaban a injuriar e insultar. En el año 1388 el síndico de la aljama, Abrafim Luquial denunciaba la presencia en el barrio de Inca del antiguo judío Jaume Bonet, el mismo durante el mes de mayo de este mismo año, se había dedicado a entrar en el nuevo barrio judío, insultar a los allí presentes e incluso a generar algunos desperfectos en las casas judías. Parece que la situación no mejoraría durante todo el año, apenas transcurridos otros treinta días se realizó un llamamiento para que nadie osara injurirar o molestar a los judíos moradores de Inca. La pena que se estableció para este momento fue muy considerable si nos atenemos a la cantidad económica que se dispone, así bajo pena de 25 libras de multa las autoridades locales volverán a insistir en la necesidad de mantener la calma y evitar los insultos hacia estos ciudadanos. Desde las autoridades reales se pretende proteger el considerado "tresor reial", incluyen medidas como la incorporación de la "vergonya pública" o "estar al costell" durante un tiempo indeterminado para aquellos que provocaran nuevos altercados o que injuriaran a los mismos ${ }^{54}$. El considerable aumento de las penas económicas impuestas así como las vergüenzas públicas que también se instauran no consiguieron apaciguar la tensa situación. Poco tiempo después, un grupo de hombres entró en el barrio judío de Inca, en esta ocasión de los insultos se pasarían a las amenazas, así las fuentes nos describen un asalto con hombres armados quienes se encargaban de asustar y amenazar a todo aquel que se encontraran en el mismo barrio o incluso fuera, siempre que fuera sospechoso de profesar dicha religión ${ }^{55}$. La situación habría llegado a tal punto que algunos judíos decidieron por estas fechas trasladar su residencia hasta la capital del reino, en la judería palmesana entendían que estaban más protegidos, aunque dicho traslado tan sólo les aseguro una momentánea y tensa calma.

53 Arxiu del Regne de Mallorca, Governació, 54, f. 47.

54 Arxiu del Regne de Mallorca, Arxiu Històric, 56, f. 130bis.

Documento citado en: ROSSELLÓ VAQUER, Ramon: Història d'Inca. 1350-1516, Lleonard Muntaner Editor, Palma, 1997, p. 98

55 Arxiu del Regne de Mallorca, Arxiu Històric, 57, f. 88. 


\section{LA RUPTURA Y LA FATALIDAD. EL ASALTO DE 1391}

En el verano de 1391, una gran masa de individuos procedentes de la part forana asaltaron Ciutat y de manera casi inmediata, destruyeron, saquearon y robaron en el barrio judío de Palma. En este asalto fueron asesinados cerca de trescientos judíos, a la vez que fueron destruidos gran parte de las viviendas, locales y tiendas que tenían ${ }^{56}$. En Inca, si nos atenemos a los acontecimientos ya narrados con anterioridad, es lógico entender que la comunidad judía no quedaría al margen de estos acontecimientos. Pese a que los testimonios conservados sobre los asaltos de los barrios judíos de Mallorca no nos detallan con la precisión que nos gustaría lo acaecido en la comarca inquera, si que conservamos algunos datos indirectos sobre los mismo. Por ejemplo, conservamos diversas reclamaciones económicas que nos indican los amplios y complejos lazos económicos que unían a la población cristiana de Inca con algunas familias judías establecidas o con operaciones económicas en dichas zonas ${ }^{57}$.

De la misma manera, también conservamos algunas denuncias que nos ofrecen interesantes datos sobre el asalto al barrio judío de Inca. Parece que durante el asalto a la ciudad de Palma, en muchos lugares se produjo cierto desgobierno y de abusos contra la población judías allá donde estuviera. Es ya bastante conocida la demanda que interpondría la conversa Clara, mujer de Salomó Pelx, en la que se señala la muerte de tres niños judíos en Inca que habría sido lanzados a un pozo ${ }^{58}$. A pesar de desconocer los hechos con exactitud, éste y otros acontecimiento se sucederían en torno al verano de 1391. Así por ejemplo, Abrafim Culitella, converso que recibía el nombre de Bernat Palo, denunciaba que en el asalto y en el saqueo del barrio judío de Inca, el barbero Joan Sunyer habría entrado en su casa y habría robado bienes $^{59}$ o la demanda de febrero de 1393, en la que el también converso

56 Para conocer mejor los acontecimientos acaecidos en Palma y también el contexto social, económico y mental, ver: LÓPEZ BONET, J.F: "La revota de 1391: efectivament, crisis social", XIII Congrés d'Història de la Corona d'Aragó, Palma, II, pp. 111-123; MAÍZ CHACÓN, J.: "Apreciaciones sobre la part forana. Mentalidad y marginalidad en el siglo XIV mallorquín (1391)", Mayurqa, 28, 2002, pp. 241-246; NIRENBERG, D.: Communities of violence. Persecution of minorities in the Middle Ages, Priceton University, Nova Jèrsei, 1998.

57 MAÍZ CHACÓN, J.: "Els mètodes crediticis jueus a la Mallorca medieval", CATEURA BENNASSER, Pau (coordinador): El crèdit i el sistema financer del Regne de Mallorca (segles XIV-XV), Edicions UIB - Consell de Mallorca, Palma, 2009, pp. 147-163.

58 Arxiu del Regne de Mallorca, Arxiu Històric, 65, f. 11v.

Ver: FAJARNÉS, E.: "Datos sobre el call de los judíos de la villa de Inca (1392)", Bolletí de la Societat Arqueologica Lul.liana, VII, 1897-1898, p. 365.

59 Arxiu del Regne de Mallorca, Arxiu Històric, 65, f. 3v.

Documento citado en: ROSSELLÓ VAQUER, Ramon: Història d'Inca..., p. 100. 
Antoni Moyá, antes llamado Vidal Catim, quien reclamaba una caja robada en la misma aljama de Inca ${ }^{60}$.

Parece ser que el asalto a Inca, arrasaría también con todo el barrio judío, tal y como sucedería en Palma, así el gobernados hacía llamamientos durante marzo de 1392 para que todo aquél que hubiera robado en los barrios judíos de Mallorca -con referencias explícitas a Inca- devolvieran lo robado. De la misma manera, se hicieron reuniones y se inició un proceso en verano siguiente para intentar cuantificar los daños producidos ${ }^{61}$. En julio de 1392, algunos conversos estimaron los albergues y los edificios que tenían en el barrio judío de Inca, un mes después, se produjo también la visita a la judería de Mateu de Lloscos, quien se dirigía al mismo con la clara intención de recuperar los bienes producidos durante el robo en dicha ciudad ${ }^{62}$. La situación de decadencia en el barrio era tal que en noviembre de 1393, se indicaba la indefensión y la soledad del mismo, tanto que en perjuicio de la Procuración Real, muchos se dedicaban a entrar en el mismo y robar vigas, tejados y otros materiales ${ }^{63}$. La situación habría alcanzado un punto de no retorno, años después encontramos algunas peticiones de protección, como la que se produce en el año 1400, en la que los conversos de Mallorca reclamaban que cuando fueran a la villa de Inca no fuesen maltratados por las autoridades locales $^{64}$, o bien, como ejemplo los procesos inquisitoriales que se producían por aquel entonces en el año 1411, por cometer delitos contra la fe $\mathrm{e}^{65}$, aunque los conversos y su posterior persecución no son motivos de este estudio.

60 Arxiu del Regne de Mallorca, Arxiu Històric, 63, f. 72v.

61 Arxiu del Regne de Mallorca, Arxiu Històric, 64, f. 39.

62 Idem., f. 155v.

63 Arxiu del Regne de Mallorca, Arxiu Històric, 66, f. 75v.

64 Arxiu del Regne de Mallorca, Arxiu Històric, 78, f. 132.

Documento citado en: ROSSELLÓ VAQUER, Ramon: Història d'Inca..., p. 109.

65 Arxiu del Regne de Mallorca, Arxiu Històric, 90, f. 335.

Documento citado en: ROSSELLÓ VAQUER, Ramon: Història d'Inca..., p. 114. 